\title{
Speaking with an Accent: Some Practical Advice for Foreign First-Time Teachers
}

Ramiro Berardo, Consejo Nacional de Investigaciones Científicas y Técnicas (Universidad Católica de Córdoba, Argentina) and University of Arizona

ABSTRACT The majority of Ph.D. programs in political science in the United States provide some kind of teaching training for graduate students, which ranges from assisting other instructors to designing and teaching new courses. In most cases, departments make an effort to guide these students in their new role as instructors; however, first-time teachers whose first language is not English do not usually receive any special guidance on how to successfully address the challenge of communicating effectively with their students-an all-too-real problem for many foreign instructors. This article provides some basic tips for improving the communication process that develops in the classroom, and is particularly tailored for individuals whose first language is not English and who are about to take the first steps of their teaching careers.

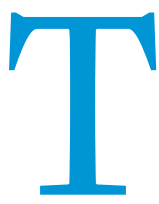

he system of higher education in the United States has historically benefited from a virtually inexhaustible inflow of human resources from foreign countries, which has contributed greatly to the generation of knowledge in all disciplines. This trend continues nowadays as more and more students are coming to the United States to further their education and pursue professional careers. Currently, one of every three Ph.D.s is awarded to a foreign national (Fiegener 2009).

In the social sciences, historical trends of earned doctoral degrees show that the percentage of doctorates awarded to foreign nationals has grown in the last decades, from approximately $14 \%$ in 1970 to almost $24 \%$ in 2007 (Welch 2008; National Opinion Research Center 2010). One benefit of this trend is the cultural diversity that foreign nationals bring into the classroom, first as students and eventually as teachers. Another benefit concerns teaching, which is an activity of great importance for many foreign graduate students, since they financially depend on it. The most recent data on doctoral degrees awarded in the United States show that in $2006,19.7 \%$ of graduate students who are U.S. citizens supported themselves mainly through teaching assistantships, while this percentage grew to over $30 \%$ for graduate students who were non-U.S. citizens. As time passes, more and more foreign students are filling teaching roles in American universities and colleges (Thurgood, Golladay, and Hill 2006).

Unfortunately, though, many institutions of higher education in the United States do not pay enough attention to the fact that foreign instructors stepping into American classrooms for the first

Ramiro Berardo is a researcher with the National Council of Scientific and Technical Research in Argentina (housed at the Catholic University of Córdoba) and an assistant research professor in the School of Government and Public Policy at the University of Arizona. He has been teaching in the United States since 20o3. He can be reached at berardo@email.arizona.edu. time must deal with unique challenges that can affect their performance in critical ways. For many of these instructors, one of the greatest problems they will encounter when assuming teaching responsibilities is that of communicating in a language that is not their native one. ${ }^{1}$ On occasion, this may be a great source of anxiety for foreign graduate students making their debut as teachers.

What follows here are some simple guidelines to overcome the common communication problems that are likely to arise for instructors who will be teaching in a language that is not native to them. The discussion is informed by both my own experiences as a foreign teacher in the United States and frequent conversations I have had with colleagues and friends who face these challenges every time they teach a class but have found ways of improving the quality of the communication process with their students. $^{2}$

\section{COMMUNICATING EFFECTIVELY (WHEN YOU TALK)}

In one of the first articles published in PS on the subject of teaching political science, Leonard Fein claimed that an important part of a teacher's job is to "think out loud, an activity that is most convincing when it is unprogrammed" (Fein 1969, 305). As you progress in your teaching career, you will probably learn to appreciate the truth of this statement. Teaching involves speculation, and the process of thinking out loud in an unprogrammed way may be helpful in developing arguments and promoting classroom discussion. However-and particularly in the case of instructors who do not speak perfect English-unprogrammed, out-loud thinking may lead to a lack of clarity as an unwanted byproduct. In my first experience in the classroom, teaching a summer course, I suffered from this problem almost daily. In my desire to engage students, I jumped from subject to subject as I thought was needed. The problem, however, was that at that point, my spoken English 
was not as good as it needed to be to result in speculation that was both unprogrammed and clear. In itself, less-than-perfect English does not have to be a huge problem: it is only logical that foreigners will make mistakes when speaking a language that is not their native one. However, the frequency of the mistakes you make can affect your effectiveness, so it is essential to minimize such mistakes. If engaging in "unprogrammed thinking" equals "unclear message," you should reassess the net benefits of using this approach.

A second issue to keep in mind that is closely related to the previous one is that your foreign accent will influence the communication process as well. A subtle accent will not cause major problems, but unfortunately, a heavy accent can be a disadvantage in the classroom (Morris 1993), at least in the initial meetings of a course, when students may require time to adjust to it. The human brain decodes phonemes (the bits that compose a continuous stream of sound) at a rapid speed but needs to continuously adjust and "guess meaning" when it faces new and unfamiliar sounds (Lund 2003). I remember feeling frustrated the first few times I lectured, because I realized that my pronunciation was affecting communication with some students. This frustration is natural if you have a heavy accent, but eventually, students will become used to the nuances of your pronunciation after a few meetings. Until then, there are a few things you can do to facilitate communication.

First, always write down your main ideas before you get to the classroom. I find that this preparation allows me to clarify concepts and general opinions about the subject, resulting in an easier transference of the material to the students. PowerPoint may help accomplish this goal, provided you teach in a classroom that is properly equipped to project slides. However, if you do not like PowerPoint or do not have the technical capabilities to use the software in the classroom, you can still create a rough plan to address course issues by writing down your ideas. A simple notepad will suffice. Of course, I am not suggesting that you take notes and then read them word-for-word in the classroom-that would be extremely boring for both the students and yourself! Think of taking notes as a "clarification mechanism" that can be constructed outside the classroom to improve the quality of communication inside of it.

A second way that you can improve the quality of the communication process is to strive for simplicity. Simplicity is not easy to achieve; after all, in our discipline, we deal with complex phenomena that demand complex thinking. But remember that in the classroom, it is always preferable to put forward one clear idea rather than two unclear ones. As your teaching skills improve, you will probably become more comfortable and able to step out of your comfort zone and engage in more unprogrammed, complex discussions. However, as you take your first steps as a teacher, try to keep things simple enough to deliver your points without leading to unnecessary confusion.

Another simple recommendation is to let your students help you clarify ideas. Many times, a student can assist you to find the right word for a sentence or restate an idea in more simple terms. Do not interpret student help as a sign of weakness-there is nothing wrong with acknowledging a verbal limitation. In fact, allowing students to help clarify ideas may increase your chances of succeeding as a teacher, because students usually appreciate the opportunity to contribute to the clarification of an argument. What are some of the ways that you can promote this kind of interaction? You might ask students to restate the points you have made every once in a while or have them summarize the main take-home lessons at the end of the meeting. In this way, you can gauge how well your students are processing the content that you are transmitting, and you can make adjustments accordingly.

Fourth, speak slowly and do not get carried away when you lecture. It is very easy for students to get lost if, in addition to your accent, you speak quickly. Pace yourself and give listeners the chance to process the information you deliver. By making these simple adjustments, you will have already won half the battle of communicating effectively.

Finally, it does not hurt to have a sense of humor about the whole situation! If you make up a word because you are thinking in your native language and trying to speak English at the same time, so be it. When that happens to me-as it still does once or twice a semester-I simply ask my students whether they understand what I mean and then just move on.

The take-home lesson here is that when you acknowledge your own limitations as a communicator, it becomes much easier to be an effective teacher, because you can take actions to improve how you communicate. The simple recommendations here may offer a good place to start.

\section{COMMUNICATING EFFECTIVELY (WHEN YOU DO NOT TALK)}

Learning how to communicate effectively takes time and practice, and regardless of how much advice you get, you will need to make your own mistakes and discover through your own experiences what works for you. So far, we have covered one part of the story: what happens when you talk. What is perhaps more important is what happens when you do not. Widespread agreement exists among educators that the learning experience can be greatly improved by promoting students' active participation, and so it is always necessary to keep in mind that teaching does not simply equal lecturing.

Nonstop lecturing will most likely lead to boredom and disengagement among your students, which means that at the end of the day, they will not have learned nearly as much as they could have about the subject matter. It is probably a good idea to avoid viewing your students as people you need to impress intellectually, and to see them more as co-teachers who have the ability to meaningfully contribute to their own education. In other words, it is advisable that you promote participation in the classroom to the maximum possible extent (O'Leary 2002).

Every teacher should favor a participatory role for students in the classroom, but foreign teachers may find this approach especially useful, because, to some extent, it removes the burden of having to constantly communicate effectively though spoken language alone. I have reduced the amount of time I spend lecturing to approximately $30 \%$ of the entire time allocated to a class. For example, in a 50-minute class, I try to limit lecturing time to no more than 15 to 20 minutes at the beginning of the session, and I devote the rest of the time to in-class activities that foster direct involvement of the students with the subject. Everything else being equal, shorter periods of lecture time help students stay focused (Bligh 2000), which benefits the instructor as well. I find that I tend to make fewer mistakes and clearer arguments when I lecture for shorter periods of time and favor other activities such as group discussions, debates, and simulations.

For instance, in one of the undergraduate classes I teach, an introductory course on Latin American politics, I have experimented with the use of filmed documentaries in conjunction with 
study guides that I distribute to students a few days ahead of class. The study guides contain questions about the readings for the day that must be answered prior to coming to class, as well as questions to be answered after watching the scheduled documentary. I begin each class with a 5 -minute quiz, introduce the subject of the day in more detail, and then screen the documentary. Finally, I moderate a discussion, which includes a conversation about the study guide questions. This format has thus far provided the best results in terms of achieving lively and productive discussions in the classroom.

In this case, communication takes place both outside and inside the classroom, since the study guide helps students process the material before we meet to discuss it. Understanding the communication process with your students as being much more than the mere exchange of information that takes place during scheduled meetings is a major key to a successful learning experience, for both your students and yourself.

\section{CONCLUDING REMARKS}

In the previous two sections, I share a few simple guidelines that can help you become a better communicator when you first enter an American classroom. Of course, these guidelines are not carved in stone, and their application will not always guarantee a smooth communication process. You must keep in mind that every time you engage in a new activity, you are bound to make mistakes along the way. So no matter what advice you may receive, the process of learning to communicate effectively with your students will take time.

Unfortunately, we can rarely control all the variables that affect our teaching effectiveness. For instance, if you agree with O'Leary that promoting student participation in the classroom is a good idea ("turning it inside out" as she puts it), then it is almost always preferable to teach small classes, because their size makes it easier for the instructor to design activities that include all students. Unfortunately, most of the time, the size of the class will not be under your control, so you will have to be able to constantly readjust and adapt your teaching style to externally imposed conditions.

The good news is that even in these cases, you can still dramatically improve your chances of succeeding as a teacher if you address common challenges to effective communication. Be structured, strive for simplicity, do not rush, and promote critical thinking through a participatory classroom approach. As well, remember that many others have undergone the same experience. In any political science department in the United States, chances are that somebody (whether a graduate student or a faculty member) would feel more comfortable teaching his or her classes in a language other than English. Those are the folks with whom you need to talk before you become a teacher, because usually, they will be able to give you hints on how to better your communication skills.

Regardless of the availability of this type of expertise in your home department, keep in mind that your students are the greatest source of information on how to improve communication. Nobody can help you hone your communication skills more than they, because they are the ones who ultimately will have to listen to you and understand what you are trying to convey. I like to administer an anonymous and informal "teaching evaluation" in the middle of the semester to help me reassess my strengths and weaknesses as a communicator-from the viewpoint of my students. Other ways of monitoring yourself and your ability to convey information properly to your students might be formulated as well.

Finally, learn to deal with frustration. Most of us who have spoken to a crowd in a foreign language with the mission of promoting learning have felt bewildered and disoriented at times. Nonetheless, you need to keep things in perspective and remember that the U.S. system of higher education is incredibly receptive to different teaching approaches and embraces diversity inside the classroom. Although your communication skills may not initially be on par with those of your American colleagues, you probably have other benefits to offer to your students that others cannot. After all, the way we speak shapes our understanding of the world around us in unique ways (Deutscher 2010), and this different outlook can only add to the enriching experience of spending time with others in a learning environment..

\section{NOTES}

I thank Simon Andrew, John García, Edgar Ramírez de la Cruz, and Luciano Venezia for their useful comments on a first draft of this article.

1. According to the Survey of Earned Doctorates (National Opinion Research Center 2010), there are only two English-speaking countries-England and Canada-that consistently appear among the 30 countries that contribute the highest number of social science Ph.D. students in U.S. institutions. In no other countries that make this list year after year is English an official language.

2. Improving the way we communicate with students is a challenge that all teachers face, regardless of their native language. Thus, some of the ideas I present here may aid first-time teachers in general, and not only those who speak English as a second language.

\section{REF E R E N C E S}

Bligh, Donald A. 2000. What's the Use of Lectures? San Francisco, CA: Jossey-Bass.

Deutscher, Guy. 2010. Through the Language Glass: Why the World Looks Different in Other Languages. New York: Metropolitan Books.

Fein, Leonard. 1969. "Teaching Political Science." PS: Political Science and Politics 2 (3): $303-07$.

Fiegener, Mark K. 2009. "Numbers of U.S. Doctorates Awarded Rise for Sixth Year, but Growth Slower." Directorate for Social, Behavioral, and Economic Sciences, National Science Foundation. http://www.nsf.gov/statistics/infbrief/ nsf10308/nsf10308.pdf.

Lund, Karen. 2003. "Age and Accent." Sprogforum 26: 9-17.

Morris, Michael A. 1993. “Teaching Political Science in a Foreign Language.” PS: Political Science and Politics 26 (1): 72-75.

National Opinion Research Center. 2010. "Survey of Earned Doctorates." http:// www.norc.org/projects/survey+ of + earned + doctorates.htm.

O'Leary, Rosemary. 2002. “Advice to New Teachers: Turn It Inside Out.” PS: Political Science and Politics 35 (1): 91-92.

Thurgood, Lori, Mary J. Golladay, and Susan T. Hill. 2006. U.S. Doctorates in the 2oth Century. National Science Foundation. Special Report NSF 06-319. http://www.nsf.gov/statistics/nsfo6319/.

Welch, Vincent, Jr. 2008. Doctorate Recipients from United States Universities: Selected Tables 2007. Chicago: National Opinion Research Center. 


\section{CAMBRIDGE}

\section{JOURNALS}

Published through the cooperation of the

History Department at Saint Louis University and the Institute for Policy History

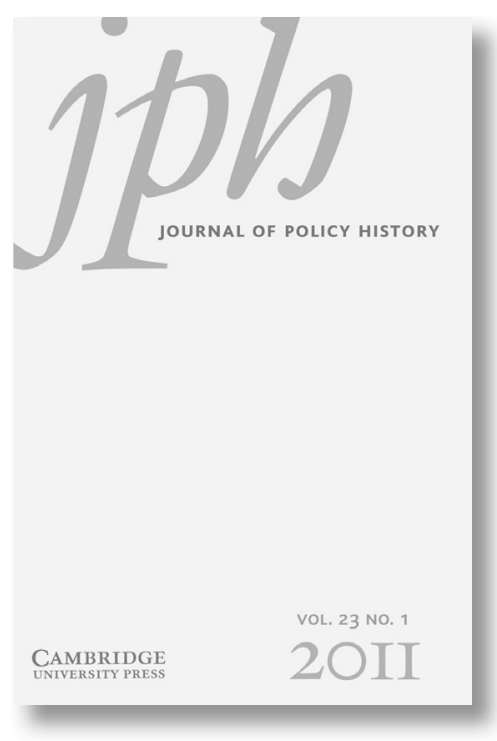

Journal of
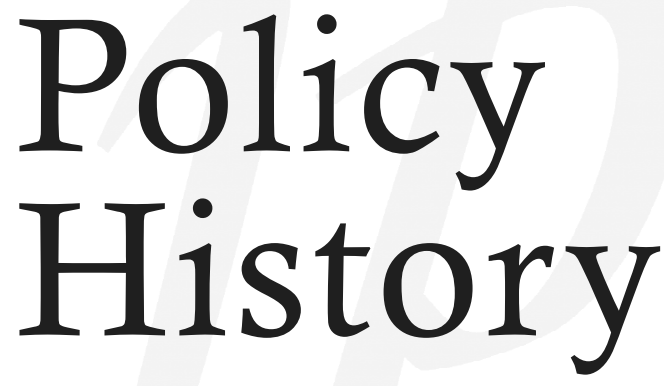

Editor-in-Chief:

Donald T. Critchlow, Saint Louis University

The Journal of Policy History is an interdisciplinary journal concerned with the application of historical perspectives to public policy studies. While seeking to inform scholars interested in policy history, the journal also seeks to inform policy makers through a historical approach to public policy. Its authors, considering public policy primarily in the United States though also in other nations, focus on policy origins and development through historical inquiry, historical analysis of specific policy areas and policy institutions, explorations of continuities and shifts in policy over time, interdisciplinary research into public policy, and comparative historical approaches to the development of public policy.

$\boldsymbol{F} \boldsymbol{R} \boldsymbol{E}$ email alerts. Keep up-to-date with new material. Sign up at: journals.cambridge.org/jph-alerts

Recommend Journal of Policy History directly from its homepage FREE online access for you when your library subscribes.

\section{journals.cambridge.org/jph}

